\title{
Insulin Regulates Apolipoprotein B Turnover and Phosphorylation in Rat Hepatocytes
}

Timothy K. Jackson.* Arthur I. Salhanick, " John Elovson, ${ }^{*}$ Margit L. Deichman, * and John M. Amatruda*

*Endocrine-Metabolism Unit, Department of Medicine, University of Rochester School of Medicine and Dentistry, Rochester, New York 14642; and ${ }^{\ddagger}$ Lipid Research Laboratory, Wadsworth Medical Center, Veterans Administration, Los Angeles, California 90073

\begin{abstract}
Our laboratory has previously shown that insulin inhibits the secretion of newly-synthesized and immunoreactive apo $B$ from rat hepatocytes. We have also shown that apo $B$ is secreted as a phosphoprotein and that phosphorylation is increased in hypoinsulinemic nonketotic diabetes. The present studies were conducted to determine whether the ability of insulin to inhibit apo $B$ secretion is related to alterations in apo $B$ turnover and whether insulin itself affects apo B phosphorylation. Pulsechase studies with $\left[^{35}\right.$ S]methionine in primary cultures of hepatocytes from normal rats in the absence and presence of insulin show that the secretion of apo B100 and apo B48 are inhibited by insulin and that this inhibition may be due in part to enhanced intracellular degradation. In addition, there is a second intracellular apo $\mathbf{B 4 8}$ pool which is not insulin regulated or degraded. In experiments in which hepatocytes were incubated with $\left[{ }^{32} \mathbf{P J o r t h o p h o s p h a t e , ~ i n s u l i n ~ d e c r e a s e d ~}{ }^{32} \mathbf{P}\right.$ incorporation into apo B100 (42\%) with only small effects on apo B48 (11\%). The small insulin effect on apo B48 may relate to an insulin-insensitive apo B48 intracellular pool. These studies show that insulin can affect the intracellular turnover, secretion, degradation, and phosphorylation of apo $B$ and emphasize the differential regulation of apo B100 and apo B48 with regard to these parameters in rat liver. (J. Clin. Invest. 1990. 86:1746-1751.) Key words: insulin • apolipoprotein B • hepatocytes
\end{abstract}

\section{Introduction}

Hepatically synthesized apo B is necessary for the normal assembly and secretion of VLDL (reviewed in reference 1). The peripheral metabolism of VLDL and apo B in part determine the level of circulating LDL cholesterol (2). Because both LDL cholesterol (3) and apo B100 (4) levels are associated with

Address reprint requests to Dr. John M. Amatruda, Endocrine-Metabolism Unit, Box 693, Dept. of Medicine, University of Rochester School of Medicine and Dentistry, 601 Elmwood Ave., Rochester, NY 14642.

Dr. Jackson's present address is Dept. of Medicine, West Virginia University Medical Center, Morgantown, WV 26506

Received for publication 28 December 1989 and in revised form 8 August 1990.

J. Clin. Invest.

(c) The American Society for Clinical Investigation, Inc. 0021-9738/90/11/1746/06 \$2.00

Volume 86, November 1990, 1746-1751

1746

Jackson, Salhanick, Elovson, Deichman, and Amatruda atherosclerotic disease, an understanding of the control of hepatic apo B synthesis and secretion is important. Acute studies in man $(5,6)$ suggest that insulin administration decreases hepatic secretion of VLDL. Using primary cultures of rat hepatocytes (7-11) and HepG2 cells $(12,13)$, we $(7,8)$ and others $(9-13)$ have shown that insulin exposure for $<24 \mathrm{~h}$ inhibits the secretion of VLDL (8-12) and apo B (7, 8, 11-13). In contrast, chronic in vivo and in vitro hyperinsulinemia stimulates VLDL secretion (reviewed in reference 14). These apparent contradictions may be best explained by the possibility that hyperinsulinemia induces resistance to the ability of insulin to alter apo B metabolism (14).

The mechanisms by which insulin acutely inhibits hepatic apo B secretion are unknown. Davis and co-workers $(15,16)$ recently showed that there is substantial intracellular turnover of both apo B48 and apo B100 in rat hepatocytes cultured in the presence of insulin (15) and these cells secrete apo B as a phosphoprotein with phosphorylation of serine residues (16). The specific effects of insulin are, however, unclear because in these studies no incubations in culture media lacking insulin were performed. We have shown that the secretion of both newly-synthesized and immunoreactive apo $B$ is reduced in primary cultures of hepatocytes from hypoinsulinemic nonketotic diabetic rats (17) and is associated with an increase in phosphorylation of apo $B$ on both tyrosine and serine residues (18). Phosphorylation of apo B may be an important modulator of the intracellular assembly and secretion of VLDL as demonstrated for vitellogenin (19). In the chick hepatocyte, phosphorylation of vitellogenin is mandatory for secretion of VLDL particles (19). Thus, insulin may be affecting the secretion of apo B from the liver by altering its intracellular turnover and phosphorylation. In addition, these effects may be time dependent.

In this report we have investigated whether alterations in intracellular apo B turnover and phosphorylation are associated with insulin's inhibition of apo B secretion.

\section{Methods}

Materials. All culture supplies, reagents, and animals were obtained from sources previously described (8). Pansorbin cells were from $\mathrm{Cal}-$ biochem-Behring Corp. (La Jolla, CA) and carrier-free $\left[{ }^{125} \mathrm{I}\right]-\mathrm{Na}$, $\left[{ }^{32} \mathrm{P}\right]$ orthophosphate, and $\left[{ }^{35} \mathrm{~S}\right]$ methionine (sp act $>800 \mathrm{Ci} / \mathrm{mmol}$ ) were obtained from Amersham Corp. (Chicago, IL).

Preparation of hepatocytes. Freshly-isolated hepatocytes were prepared from ad libitum fed male Sprague-Dawley rats as previously described (20). Primary cultures of hepatocytes (8) were maintained on collagen-coated plates in serum-free DME for $18 \mathrm{~h}$.

Pulse-chase incubations. After overnight culture, the monolayers were switched to a methionine-free modified DME (8). Six plates each 
were incubated for an additional $2 \mathrm{~h}$ in the absence and presence of insulin $(100 \mathrm{nM})$ after which an identical amount of $\left[{ }^{35} \mathrm{~S}\right]$ methionine $(90-190 \mu \mathrm{Ci} / \mathrm{ml})$ was added to each of the 12 plates within an experiment. After 15 min of incubation, the plates were placed on ice and the media replaced with $4.2 \mathrm{ml}$ of DME containing unlabeled methionine $(10 \mathrm{mM})$ (chase medium) and the incubation continued at $37^{\circ} \mathrm{C}$. Insulin was readded to plates previously exposed to insulin. Incubations were terminated at $0,10,20,45,90$, and $180 \mathrm{~min}$ after the addition of chase medium (15). The media were removed and immediately mixed with equal volumes of a quench solution consisting of PMSF ( $1 \mathrm{mM})$, EDTA (4 mM), sodium azide $(0.1 \%$, wt/vol), $N$-ethylmaleimide ( 8 $\mathrm{mM})$, aprotinin $(1,000 \mathrm{U} / \mathrm{ml})$, soybean trypsin inhibitor $(0.01 \%$, wt/ $\mathrm{vol}$ ) and $0.001 \%$ (wt/vol) of leupeptin, pepstatin, antipain, and chymostatin. The monolayers were washed with ice-cold PBS, pH 7.4, and the cells recovered by scraping in PBS followed by centrifugation (200 g, $5 \mathrm{~min})$. Lysis solution $(0.5 \mathrm{ml})$ consisting of Tris- $\mathrm{HCI}(50 \mathrm{mM}, \mathrm{pH}$ $8)$, Triton X-100 (3\%, vol/vol), sodium sarcosylate (1\%, wt/vol), SDS $(0.3 \%, \mathrm{wt} / \mathrm{vol})$, aprotinin $(1,000 \mathrm{U} / \mathrm{ml})$, soybean trypsin inhibitor $(0.01$ $\mathrm{U} / \mathrm{ml})$, sodium orthovanadate $(20 \mathrm{mM})$, PMSF (2 mM), EDTA (1 $\mathrm{mM}), N$-ethylmaleimide $(8 \mathrm{mM})$, and $\mathrm{NaF}(10 \mathrm{mM})$ was added to the cell pellets and the mixtures vortexed and centrifuged $(10,000 \mathrm{~g}, 10$ min). The supernatants were removed and mixed with equal volumes of $2 \mathrm{M} \mathrm{LiCl}$. Media and cellular extracts were precleared using normal rabbit serum (21) and the ${ }^{35} \mathrm{~S}$-labeled apo B immunoprecipitated overnight at $4^{\circ} \mathrm{C}$. Protein A (Pansorbin cells, $100 \mu \mathrm{l} / \mathrm{ml}$ ) was added for $2 \mathrm{~h}$ at $4^{\circ} \mathrm{C}$. The samples were centrifuged, the supernatants removed, and subjected to two additional overnight immunoprecipitations. Preliminary experiments established that complete recovery of ${ }^{35} \mathrm{~S}$-labeled apo B48 and apo B100 from cell extracts and media was achieved using three sequential immunoprecipitations. The pellets from each immunoprecipitation were combined, washed, and boiled in Tris-HCL buffer, ( $80 \mathrm{mM}, \mathrm{pH} 6.8)$, containing SDS (3.8\%, wt/vol), mercaptoethanol ( $5 \%, \mathrm{vol} / \mathrm{vol})$, and glycerol (10\%, vol/vol). Insoluble material was removed by centrifugation, the supernatants made $2 \mathbf{M}$ in urea, and subjected to SDS-PAGE (22) in a $4 \%$ gel containing $1 \mathrm{M}$ urea. After Coomassie blue staining, gels were destained, dried, autoradiographed, and scanned with a Bromma Ultroscan XL laser densitometer (LKB Instruments, Inc., Gaithersburg, MD). Apo B band development was in a linear range.

Apo B phosphorylation. Freshly-isolated hepatocytes were preincubated in serum-free Waymouth's medium (20). Final cell suspensions $\left(5-10 \times 10^{6} \mathrm{cells} / \mathrm{ml}\right)$ in Waymouth's medium containing $\left[{ }^{32} \mathrm{P}\right]$ orthophosphate $(2 \mathrm{mCi} / \mathrm{ml})$ were incubated for $60 \mathrm{~min}$ in the absence of insulin. Insulin (100 $\mathrm{nM})$ was then added to one-half of the cells. After $90 \mathrm{~min}$, the incubation was terminated by rapid centrifugation. Cells were immediately solubilized with $2 \mathrm{ml}$ of lysis solution and mixed with $\mathrm{LiCl}$ as described above. After overnight dialysis at $4^{\circ} \mathrm{C}$ against PBS, pH 7.4, containing protease and phosphatase inhibitors, the dialysates were centrifuged and apo B immunoprecipitated as described above except that preclearing with normal rabbit serum was omitted. SDS-PAGE was performed as described above except that $3.5-12 \%$ linear gradient gels were employed. To establish that electrophoretically separated apo B bands were completely delipidated, samples of rat serum VLDL were identically solubilized, run on SDS-PAGE, and apo B100 and apo B48 electroeluted from the gel. Both peptides were completely devoid of free fatty acids as analyzed by gas chromatography-mass spectroscopy (data not shown).

Apo $\mathrm{B}$ antibody. Rabbit polyclonal antibodies to apo B100 and B48 were made from rat VLDL as described by Davis et al. (16). The antibody was tested against an affinity purified rat apo B antibody (23). Both antibodies immunoprecipitated the same bands from unlabeled VLDL, ${ }^{125} \mathrm{I}$-labeled VLDL, and ${ }^{35} \mathrm{~S}$-labeled intracellular and secreted material. In addition, the same bands were identified on Western blots of rat VLDL, and immunoprecipitated material from solubilized hepatocytes and hepatocyte media. Hepatocytes contain three intracellular immunoprecipitable phosphoproteins identified as apo B100, apo B97, and apo B48 using iodinated VLDL as a standard. This was confirmed by Western blots of VLDL and intracellular immunopre- cipitated apo B using both antibodies. Apo B100 and apo B97 are designated in our study as apo B100.

Statistical analysis. Statistical analysis were performed using Student's paired $t$ test.

\section{Results}

Intracellular apo $B$ turnover and secretion. To evaluate the effects of insulin on intracellular apo B turnover, we performed pulse-chase experiments in primary cultures of rat hepatocytes as described in Methods. Data representing the results from five experiments are shown in Fig. 1 and Table I. The data shown in Fig. 1 represent the mean \pm SEM of apo $B$ content at each time point and the data shown in Table I represent the mean \pm SEM of the respective peak values from each experiment (see table legend). By either presentation, in hepatocytes untreated with insulin, there is greater intracellular accumulation of newly-synthesized apo B48 than apo $B 100$. In contrast to a nearly twofold higher intracellular level of apo B48 present, the absolute amounts of apo B48 and apo B100 depleted from hepatocytes after $180 \mathrm{~min}$ of cold methiontne chase are comparable $(18.3 \pm 4.3$ and $15.7 \pm 2.1 \mathrm{U} / \mathrm{mg}$ protein, respectively) as is the amount of apo B secreted from these cells $(13.5 \pm 1.2$ and $11.0 \pm 2.4 \mathrm{U} / \mathrm{mg}$ protein representing media recoveries of 74 and $70 \%$ for apo B48 and apo B100, respectively). In the absence of insulin, the amount of intracellular apo B48 (4.9 $\pm 4.7 \mathrm{U} / \mathrm{mg}$ protein) and apo B100 $(4.7 \pm 3.3 \mathrm{U} / \mathrm{mg}$ protein) degraded represents $\sim 27-30 \%$ of the apo B48 or apo B100 depleted from the cell.

Although the absolute amounts of apo B48 and apo B100 secreted and degraded in the absence of insulin are comparable, the turnover rates of intracellular apo B48 and apo B100 differ substantially. By 90 min after the cold methionine chase, $34 \%$ of the newly-synthesized apo B48 has disappeared from the cells (intracellular peak, $28.5 \pm 4.0 \mathrm{U} / \mathrm{mg}$ protein; amount depleted, $9.7 \pm 1.7 \mathrm{U} / \mathrm{mg}$ protein) compared to an $83 \%$ depletion of apo B100 (intracellular peak, $16.8 \pm 2.1 \mathrm{U} / \mathrm{mg}$ protein; amount depleted, $13.9 \pm 1.9 \mathrm{U} / \mathrm{mg}$ protein). By $180 \mathrm{~min}$ after the cold methionine chase, the depletions of apo B48 and apo B100 equal $64 \%$ (intracellular peak, $28.5 \pm 4.0 \mathrm{U} / \mathrm{mg}$ protein; amount depleted, $18.3 \pm 4.3 \mathrm{U} / \mathrm{mg}$ protein) and $93 \%$ (intracellular peak, $16.8 \pm 2.1 \mathrm{U} / \mathrm{mg}$ protein; amount depleted, $15.7 \pm 2.1 \mathrm{U} / \mathrm{mg}$ protein), respectively. Calculation of the halflives of the two apo B variants from untreated hepatocytes gives values of 125 and $43 \mathrm{~min}$ for apo B48 and apo B100, respectively (Fig. 1, insets).

In accordance with our previous studies $(7,8)$, the addition of insulin causes a reduction ( 27 and $35 \%$, respectively, at 180 $\mathrm{min}$ ) in the amount of newly-synthesized ${ }^{35} \mathrm{~S}$-labeled apo B48 $(13.5 \pm 1.2$ reduced to $9.9 \pm 1.4 \mathrm{U} / \mathrm{mg}$ protein, $P<0.05)$ and apo B100 (11.0 \pm 2.4 reduced to $7.1 \pm 1.9 \mathrm{U} / \mathrm{mg}$ protein, $P$ $<0.05)$ peptides chased into the media compared to the control without insulin (Fig. 1, Table I). This effect is now shown to be posttranslational in nature because insulin has no significant effect on the rates of synthesis of labeled apo B peptides during the $\left[{ }^{35}\right.$ S ]methionine pulse (Table I). Furthermore, the ability of insulin to inhibit both apo B48 and apo B100 secretion is not related to any significant changes in the half-lives of the two apo B variants (Fig. 1, insets, 139 and $31 \mathrm{~min}$, respectively). In the presence of insulin, the amount of apo B48 and apo B100 degraded intracellularly is substantially increased but the time dependency of insulin's effects on these parame- 


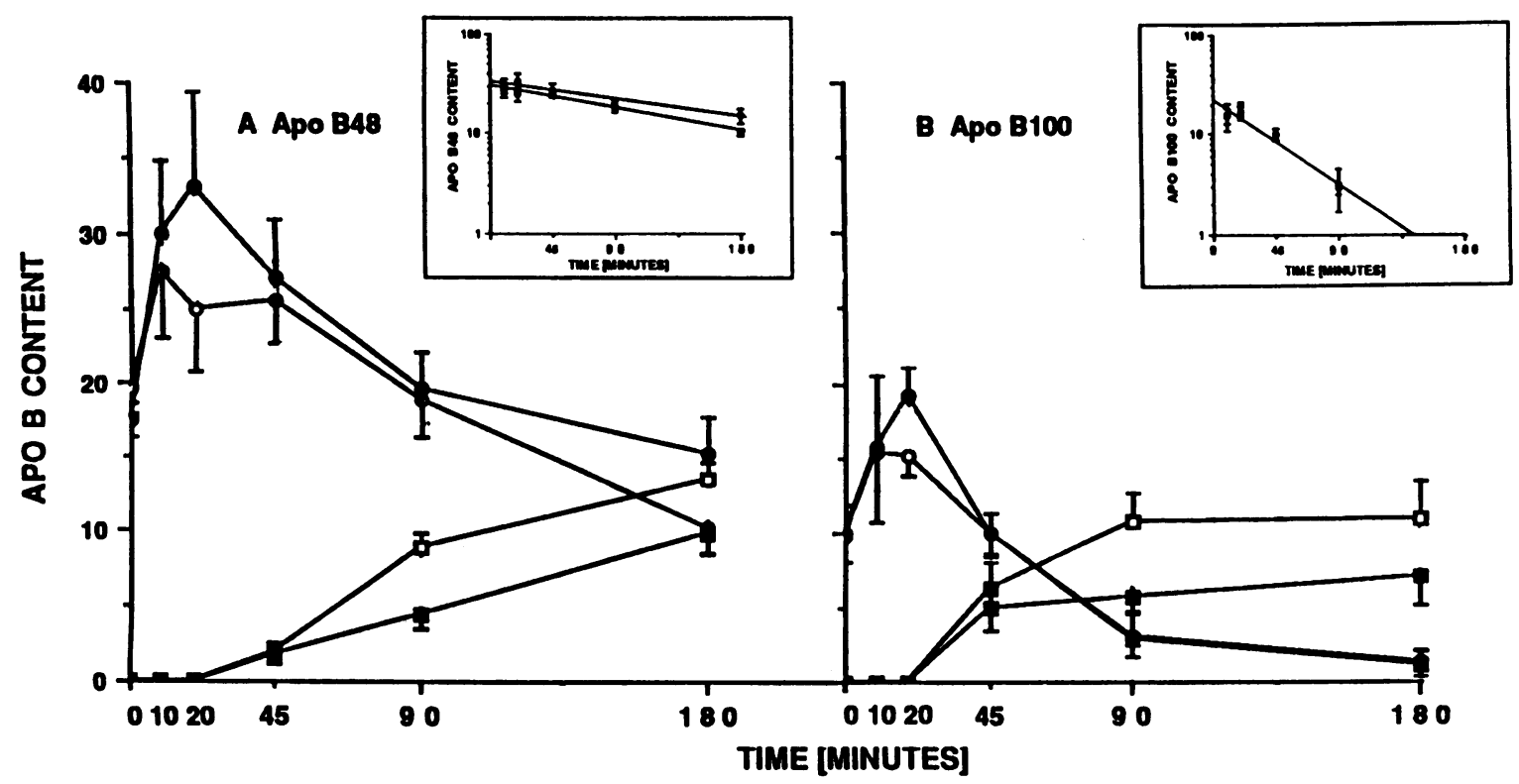

Figure 1. Pulse-chase labeling of apo B in primary cultures of rat hepatocytes. Newly-synthesized apo B48 $(A)$ and apo B100 (B) from untreated $(O D)$ and insulin-treated $(100 \mathrm{nM}, \bullet \square)$ hepatocytes were labeled with $\left[{ }^{35} \mathrm{~S}\right]$ methionine and chased with cold methionine for various times up to $180 \mathrm{~min}$ as described in Methods. After immunoprecipitation and SDS-PAGE, intracellular ( $(\bullet)$ and media ( $\square \bullet)$ apo B radioactivity was determined. (Ordinate) Apo B content in scanning units per milligram protein. (Abscissa) Time after cold methionine chase. The data represent the mean \pm SEM of five experiments. (Insets) First-order kinetic analysis of apo B48 $(A)$ and apo B100 $(B)$ depletion.

ters differ between apo B48 and apo B100. In the presence of insulin and after 90 min of cold methionine chase, apo B48 and apo B100 secretion are significantly inhibited (for apo $\mathrm{B} 48,8.8 \pm 1.1$ reduced to $4.5 \pm 1.1 \mathrm{U} / \mathrm{mg}$ protein representing $49 \%$ inhibition, $P<0.05$; for apo $\mathrm{B} 100,10.8 \pm 1.8$ reduced to $5.8 \pm 1.1 \mathrm{U} / \mathrm{mg}$ protein representing $46 \%$ inhibition, $P<0.05$ ) and intracellular degradation significantly enhanced (for apo B48, from $1.0 \pm 1.2$ to $11.8 \pm 3.2 \mathrm{U} / \mathrm{mg}$ protein, $P<0.05$; for apo $\mathrm{B} 100$, from $3.1 \pm 2.8$ to $12.0 \pm 3.6 \mathrm{U} / \mathrm{mg}$ protein, $P<0.01$ ). The comparable effect of insulin on the absolute amount of apo B48 and apo B100 secreted or degraded after $90 \mathrm{~min}$ of cold methionine, which is equivalent to more than two halflives for apo B100 and less than one half-life for apo B48, is not preserved when measurements of these parameters for apo B48 are made after an additional $90 \mathrm{~min}$ of chase (at $180 \mathrm{~min}$ which is equivalent to $<1.5$ half-lives for apo B48). As shown in Table I, no insulin-dependent inhibition of apo B48 secretion or enhancement of degradation are found between 90 and $180 \mathrm{~min}$

Apo $B$ phosphorylation. In initial experiments, we attempted to evaluate the effects of insulin on apo B phosphorylation in primary cultures of hepatocytes, but due to the limitation of cell number per unit volume and low incubating ${ }^{32} \mathrm{P}$ specific activities, the results were inconclusive. As an alternative, we elected to employ freshly-isolated hepatocytes. Previously, we have shown freshly-isolated rat hepatocytes to be insulin-responsive with regard to aminoisobutyric acid uptake (20) and lipid synthesis (24) and have found freshly-isolated human hepatocytes to be insulin responsive with regard to apo $B$ secretion (25). In addition, under the same incubation conditions used to evaluate apo B phosphorylation, we observed a consistent inhibition $(\sim 25 \%)$ of apo B secretion (as measured by RIA) from freshly-isolated rat hepatocytes incubated with insulin and found no detectable degradation of secreted VLDL apo $B$ as measured by isopropanol $\left({ }^{125} \mathrm{I}-\mathrm{VLDL}\right.$ precipitated; media from untreated hepatocytes, $48.1 \pm 4.6 \%$; media from insulin-treated hepatocytes, $46.1 \pm 4.1 \%$ ) and TCA precipitation $\left({ }^{125} \mathrm{I}-\mathrm{VLDL}\right.$ precipitated; media from untreated hepatocytes, $96.7 \pm 1.4 \%$; media from insulin-treated hepatocytes, $94.6 \pm 2.4 \%$ ) of exogenously added rat ${ }^{125} \mathrm{I}-\mathrm{VLDL}$. Extending our previous results with hepatocytes in culture, Fig. 2 shows that freshly-isolated hepatocytes in suspension incorporate $\left[{ }^{32} \mathrm{P}\right]$ orthophosphate into intracellular apo B. Also, ${ }^{32} \mathrm{P}$-labeling of apo B100 relative to apo B48 is very similar to that found with $\left[{ }^{35} \mathrm{~S}\right]$ methionine in the cultured hepatocytes (Fig. 1 \& Table I). The addition of $100 \mathrm{nM}$ insulin to hepatocytes for 90 min decreased ${ }^{32} \mathrm{P}$ incorporation into apo B100 with only a small decrease in ${ }^{32} \mathrm{P}$ incorporation into apo B48. This is illustrated graphically by the scan of this gel (Fig. 2 inset) demonstrating a $42 \%$ decrease in intensity of the apo B100 band with an $11 \%$ decrease in the apo B48 band.

\section{Discussion}

An understanding of the mechanisms by which insulin regulates apo B synthesis, the assembly of VLDL particles, and the secretion of VLDL are critical to our understanding of the regulation of lipoprotein production in normal physiology and in altered metabolic states such as obesity, diabetes, fasting, and glucocorticoid excess. We $(7,8)$ and others $(11)$ have shown that insulin at postprandial concentrations inhibits the secretion of apo B from primary cultures of rat hepatocytes. The present study extends these observations by examining the effects of insulin on intracellular turnover and secretion of apo B48 and apo B100. The data show that in the absence of insulin most of the intracellular newly-synthesized ${ }^{35} \mathrm{~S}$-labeled apo B48 and apo B100 depleted from the cells during a 90-min chase can be recovered in the media ( 91 and $78 \%$ for apo B48 


\begin{tabular}{|c|c|c|c|c|c|c|}
\hline \multirow[t]{6}{*}{ A. Apo B48* } & & & \multicolumn{2}{|c|}{ Intracellular peak } & & \\
\hline & & & -Insulin & +Insulin & & \\
\hline & & & $28.5 \pm 4.0$ & $35.9 \pm 5.6$ & & \\
\hline & \multicolumn{6}{|c|}{ Time interval } \\
\hline & \multicolumn{2}{|c|}{ Peak to $180 \mathrm{~min}$} & \multicolumn{2}{|c|}{ Peak to $90 \mathrm{~min}$} & \multicolumn{2}{|c|}{$90-180 \mathrm{~min}$} \\
\hline & -Insulin & +Insulin & -Insulin & +Insulin & -Insulin & +Insulin \\
\hline Depleted $^{\ddagger}$ & $18.3 \pm 4.3$ & $20.8 \pm 5.8$ & $9.7 \pm 1.7$ & $16.3 \pm 4.4$ & $8.6 \pm 2.9$ & $4.5 \pm 1.7$ \\
\hline Secreted & $13.5 \pm 1.2$ & $9.9 \pm 1.4^{\| \prime}$ & $8.8 \pm 1.1$ & $4.5 \pm 1.1^{11}$ & $4.7 \pm 1.6$ & $5.4 \pm 1.0$ \\
\hline Degraded $^{\S}$ & $4.9 \pm 4.7$ & $10.9 \pm 5.1$ & $1.0 \pm 1.2$ & $11.8 \pm 3.2^{\prime \prime}$ & $3.9 \pm 4.1$ & $-0.9 \pm 2.5$ \\
\hline \multirow[t]{7}{*}{ B. Apo B100* } & & & \multirow{2}{*}{\multicolumn{2}{|c|}{ Intracellular peak }} & & \\
\hline & & & & & & \\
\hline & & & -Insulin & +Insulin & & \\
\hline & & & $16.8 \pm 2.1$ & $20.9 \pm 3.5$ & & \\
\hline & & \multicolumn{4}{|c|}{ Time interval } & \\
\hline & & \multicolumn{2}{|c|}{ Peak to $180 \mathrm{~min}$} & \multicolumn{2}{|c|}{ Peak to $90 \mathrm{~min}$} & \\
\hline & & -Insulin & +Insulin & -Insulin & & \\
\hline Depleted $^{\ddagger}$ & & $15.7 \pm 2.1$ & $19.6 \pm 4.1$ & $13.9 \pm 1.9$ & & \\
\hline Secreted & & $11.0 \pm 2.4$ & $7.1 \pm 1.9^{\prime \prime}$ & $10.8 \pm 1.8$ & & \\
\hline Degraded $^{\S}$ & & $4.7 \pm 3.3$ & $12.5 \pm 3.3$ & $3.1 \pm 2.8$ & & \\
\hline
\end{tabular}

* All data are expressed in scanning units per milligram protein. ${ }^{\ddagger}$ Depleted apo $B$ is the difference between the peak intracellular level and that at the designated time for each experiment. $\$$ Intracellularly degraded apo B is calculated by subtracting secreted apo B from depleted apo B for each experiment. Statistical comparisons between untreated and insulin-treated hepatocytes. " $P<0.05$. $^{\top} P<0.01$.

and apo $\mathrm{B} 100$, respectively). In the presence of insulin, intracellular degradation of both apo B48 and apo B100 are substantially enhanced because only 28 and $33 \%$ of intracellularly depleted apo B48 and apo B100, respectively, are recovered in the media (Table I). Because primary cultures of hepatocytes do not take up and degrade apo B-containing particles secreted into the medium (26), the results indicate that insulindependent enhancement of apo B48 and apo B100 intracellular degradation contributes substantially to reduced apo B secretion. However, the relative contributions of the direct inhibitory effects of insulin on apo B secretion remain to be determined.

Borchardt and Davis (15) reported significant intracellular degradation of both apo B48 (40\%) and apo B100 (64\%) in rat hepatocytes cultured in the presence of insulin $(1 \mu \mathrm{g} / \mathrm{ml}, 167$ nM). Our data after $180 \mathrm{~min}$ of cold methionine chase agree with their findings (Table I, apo B48 and apo B100 degradation equal 52 and $64 \%$, respectively, in insulin-treated hepatocytes). In addition, Borchardt and Davis (15) and Swift et al. (27) have shown the secretion of apo B48 to be slower than that of apo B100 in primary cultures of hepatocytes which may relate to a larger intracellular pool of apo B48 (27). The present study confirms and extends these observations. With regard to hormonal sensitivity, we have observed that the ability of insulin to modulate apo B48 secretion and degradation is attenuated between 90 and 180 min after cold methionine chase. These observations suggest the existence of two apo B48 pools and that the acute effects of insulin as assessed with a pulsechase protocol are primarily on a more rapidly turning over pool.

In this report we have shown that the addition of insulin decreases ${ }^{32} \mathrm{P}$ incorporation primarily into apo $\mathrm{B} 100$ with less effect on apo B48. Thus, apo B100 is one of several proteins whose phosphorylation-dephosphorylation state is affected by insulin (reviewed in reference 28). Recently, Capasso et al. (29) have shown that intact rat liver Golgi vesicles translocate ATP into their cisternal space and use it to phosphorylate a set of secretory proteins. The postulated function of these phosphorylations is to render proteins (e.g., casein) resistant to proteolytic degradation (29). While our data show that in the presence of insulin and after $90 \mathrm{~min}$ of cold methionine chase, the absolute amount of apo B100 degraded is comparable with apo B48, this insulin effect on apo B48 is not seen from 90 to $180 \mathrm{~min}$ after the cold methionine chase. Relative to the peak amounts of newly-synthesized apo B100 and apo B48 present in insulin-treated cells (Table 1, 20.9 \pm 3.5 and $35.9 \pm 5.6 \mathrm{U} / \mathrm{mg}$ protein, respectively), the percentages of apo B100 and apo B48 degraded (57 and 33\% after 90 min and 60 and $30 \%$ after $180 \mathrm{~min}$, respectively) differ and may relate to the greater inhibitory effect of insulin on apo B100 phosphorylation (42 and $11 \%$ for apo B100 and apo B48, respectively) when evaluated under conditions of continuous exposure to $\left[{ }^{32} \mathrm{P}\right]$ orthophosphate. Taken together, the ${ }^{35} \mathrm{~S}$ and ${ }^{32} \mathrm{P}$ apo $\mathrm{B}$ labeling data suggest the presence of two separate hepatic pools of apo B48, 

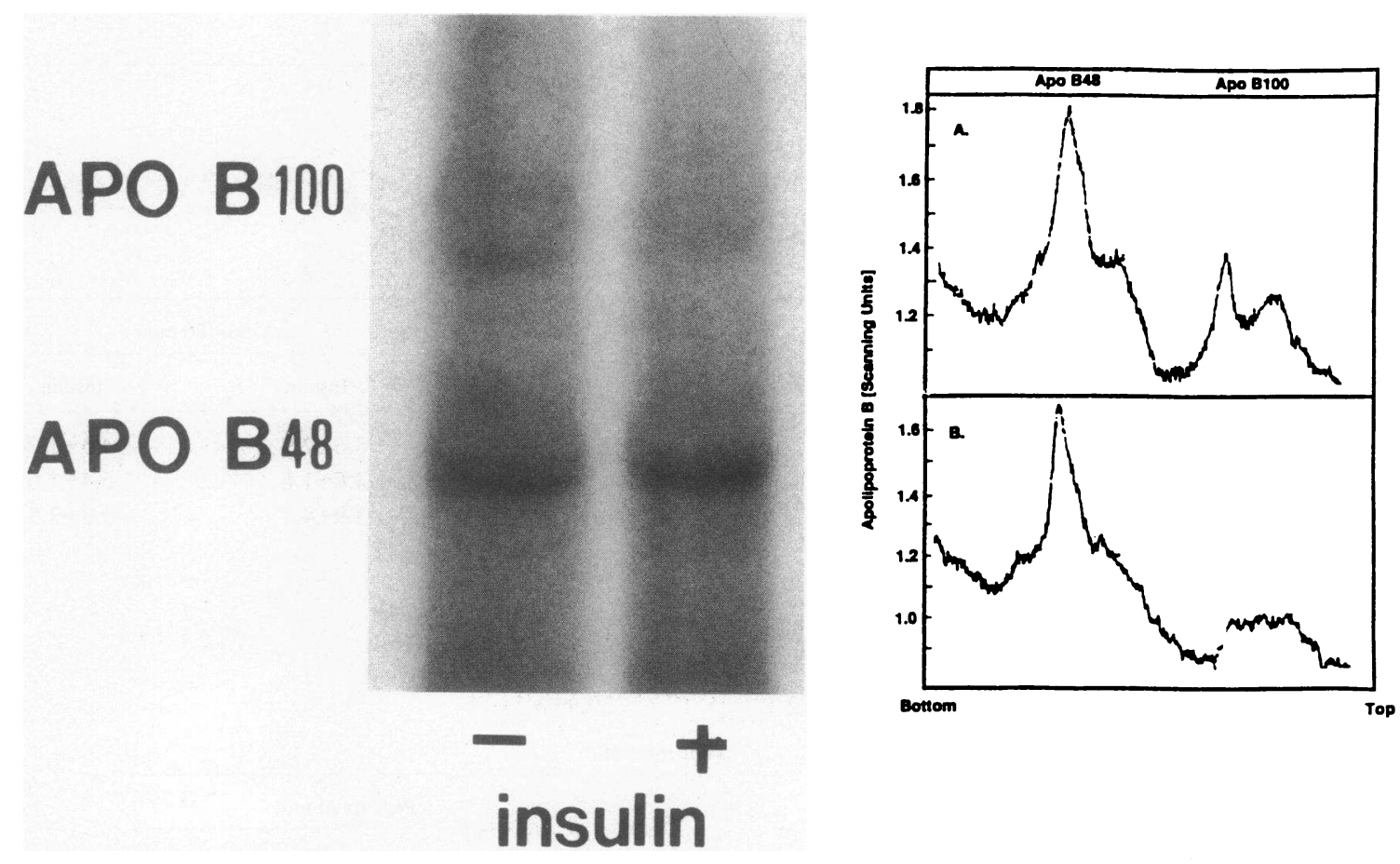

Figure 2. Incorporation of $\left.{ }^{32} \mathrm{P}\right]$ orthophosphate into intracellular apo B. Untreated and insulin-treated (100 nM) hepatocytes were labeled with $\left.{ }^{32} \mathrm{P}\right]$ orthophosphate as described in Methods. After dialysis, immunoprecipitation, and SDS-PAGE, apo B radioactivity was determined (inset). Gel scan $(A)$ Apo B from untreated hepatocytes. $(B)$ Apo B from insulin-treated hepatocytes. Apo B content is in scanning units. The data are representative of four replicate experiments.

one which is phosphorylated and constitutively secreted, and one pool which is phosphorylated but whose phosphorylation is regulated by insulin allowing for channeling into a degradative intracellular pathway. The entire apo B100 pool appears to be insulin sensitive.

Another possible role for insulin-regulated changes in the phosphorylation of intracellular apo B could be to regulate VLDL particle size. Support for a role for phosphorylation in the association of proteins and lipids comes from the studies of Powell and Glenney (30) who demonstrated that dephosphorylated calpactin 1 (lipocortin 1) had increased affinity for phosphatidylserine liposomes compared to the phosphorylated form. Thus, decreased phosphorylation of intracellular apo B100 in the presence of insulin could result in increased lipid association and VLDL particle size.

We have previously demonstrated (18) that both apo B100 and apo B48 are secreted as phosphoproteins and that phosphorylation of both peptides increased in hepatocytes from hypoinsulinemic nonketotic diabetic rats. This enhanced apo B phosphorylation could decrease the affinity of apo B for lipids thus leading to smaller, more dense VLDL particles characteristic of those secreted from livers of diabetic rats (31). However, whereas short-term insulin exposure and diabetes both lead to decreased apo B secretion, they have opposite effects on apo B phosphorylation.

In summary, these studies indicate that insulin acutely decreases the secretion of apo B48 and apo B100 and insulin's effect may, in part, be related to increased intracellular degradation. The metabolism of apo B48 and apo B100 differ with regard to intracellular turnover which may relate to the presence of an insulin-insensitive intracellular apo B48 pool. Dif- ferences in apo B48 and apo B100 metabolism are further demonstrated in that the ability of insulin to inhibit apo B phosphorylation is more clearly evident in apo B100. These multiple and divergent effects of insulin on hepatic apo B variants emphasize the complexity of mechanisms by which insulin regulates the assembly, intracellular turnover, and the secretion of VLDL particles. Because human liver secrete only apo B100, our demonstration of insulin effects on apo B100 phosphorylation and turnover may be relevant to human apo B metabolism.

\section{Acknowledgments}

This work was supported by National Institutes of Health Grant DK-20948 and the Veterans Administration. T. K. Jackson was a recipient of a James P. Wilmot Cancer Fellowship of the University of Rochester.

\section{References}

1. Olofsson, S.-O., G. Bjursell, K. Bostrom, P. Carlsson, J. Elovson, A. A. Protter, M. A. Reuben, and G. Bondjers. 1987. Apolipoprotein B: structure, biosynthesis and role in the lipoprotein assembly process. Atherosclerosis. 68:1-17.

2. Dolphin, P. J. 1985. Lipoprotein metabolism and the role of apolipoproteins as metabolic programmers. Can. J. Biochem. Cell Biol. 63:850-869.

3. Grundy, S. M. 1986. Cholesterol and coronary heart disease. JAMA (J. Am. Med. Assoc.). 256:2849-2858.

4. Brunzell, J. D., A. D. Sniderman, J. J. Albers, and P. O. Kwiterovich, Jr. 1984. Apoprotein $\mathrm{B}$ and $\mathrm{Al}$ and coronary artery disease in humans. Arteriosclerosis. 4:79-83. 
5. Pietri, A. O., F. L. Dunn, S. M. Grundy, and P. Raskin. 1983. The effect of continuous subcutaneous insulin infusion on very-lowdensity lipoprotein triglyceride metabolism in Type II diabetes mellitus. Diabetes. 32:75-81.

6. Vogelberg, K. H., F. A. Gries, and D. Moshinski. 1980. Hepatic production of VLDL triglycerides. Dependence of portal substrate and insulin concentration. Horm. Metab. Res. 12:688-694.

7. Jackson, T. K., A. I. Salhanick, J. D. Sparks, C. E. Sparks, M Bolognino, and J. M. Amatruda. 1988. Insulin-mimetic effects of vanadate in primary cuitures of rat hepatocytes. Diabetes. 37:1234-1240.

8. Sparks, C. E., J. D. Sparks, M. Bolognino, A. Salhanick, P. S Strumph, and J. M. Amatruda. 1986. Insulin effects on apolipoprotein B lipoprotein synthesis and secretion by primary cultures of rat hepatocytes. Metabolism. 35:1128-1136.

9. Bartlett, S. M., and G. F. Gibbons. 1988. Short- and longer-term regulation of very-low density lipoprotein secretion by insulin, dexamethasone and lipogenic substrates in cultured hepatocytes: a biphasic effect of insulin. Biochem. J. 249:37-43.

10. Durrington, P. N., R. S. Newton, A. B. Weinstein, and D. Steinberg. 1982. Effects of insulin and glucose on very low density lipoprotein secretion by cultured rat hepatocytes. J. Clin. Invest. 70:63-73.

11. Patsch, W., S. Franz, and G. Schofeld. 1983. Role of insulin in lipoprotein secretion by cultured rat hepatocytes. J. Clin. Invest. 71:1161-1174.

12. Dashti, N., and G. Wolfbauer. 1987. Secretion of lipids, apolipoproteins, and lipoproteins by human hepatoma cell line HepG2: effects of oleic acid and insulin. J. Lipid Res. 28:423-436.

13. Pullinger, C. R., J. D. North, B.-B. Teng, V. A. Rifici, A. E. R. de Brito, and J. Scott. 1989. The apolipoprotein B gene is constitutively expressed in HepG2 cells: regulation of secretion by oleic acid, albumin, and insulin, and measurement of the mRNA half-life. $J$. Lipid. Res. 30:1065-1077.

14. Gibbons, G. F. 1989. Insulin, diabetes and hepatic very-lowdensity lipoprotein metabolism. Biochem. Soc. Trans. 17:49-51.

15. Borchardt, R. A., and R. A. Davis. 1987. Intrahepatic assembly of very low density lipoproteins: rate of transport out of the endoplasmic reticulum determines rate of secretion. J. Biol. Chem. 262:16394-16402.

16. Davis, R. A., G. M. Clinton, R. A. Borchardt, M. MaloneMcNeal, T. Tan, and G. R. Lattier. 1984. Intrahepatic assembly of very low density lipoproteins: phosphorylation of small molecular weight apolipoprotein B. J. Biol. Chem. 259:3383-3386.

17. Sparks, J. D., C. E. Sparks, M. Bolognino, A. M. Roncone, T. K. Jackson, and J. M. Amatruda. 1988. Effects of nonketotic streptozotocin diabetes on apolipoprotein B synthesis and secretion by primary cultures of rat hepatocytes. J. Clin. Invest. 82:37-43.
18. Sparks, J. D., C. E. Sparks, A. M. Roncone, and J. M. Amatruda. 1988. Secretion of high and low molecular weight phosphorylated apolipoprotein $B$ by hepatocytes from control and diabetic rats. $J$. Biol. Chem. 263:5001-5004.

19. Wang, S.-Y., and D. L. Williams. 1982. Biosynthesis of vitellogenin: identification and characterization of non-phosphorylated precursors to avian vitellogenin I and vitellogenin II. J. Biol. Chem. 257:3837-3846.

20. Cech, J. M., R. B. Freeman, Jr., J. F. Caro, and J. M. Amatruda. 1980. Insulin action and binding in isolated hepatocytes from fasted, streptozotocin-diabetic and older spontaneously obese rats. Biochem. J. 188:839-845.

21. Kessler, S. W. 1981. Use of protein A-bearing staphylococci for the immunoprecipitation and isolation of antigens from cells. Methods Enzymol. 73:442-459.

22. Laemmli, U. K. 1970. Cleavage of structural proteins during the assembly of the head of bacteriophage T4. Nature (Lond.). 227:680-685.

23. Reuben, M. A., K. L. Swenson, M. H. Doolittle, D. F. Johnson, A. J. Lusis, and J. Elovson. 1988. Biosynthetic relationships between the three rat apolipoprotein B peptides. J. Lipid Res. 29:1337-1347.

24. Caro, J. F., and J. M. Amatruda. 1981. Evidence for modulation of insulin action and degradation independently of insulin binding. Am. J. Physiol. 240:E325-E332.

25. Salhanick, A. I., S. I. Schwartz, and J. M. Amatruda. 1990. Insulin inhibits apolipoprotein B secretion in isolated human hepatocytes. Metabolism. In press.

26. Davis, R. A., J. R. Boogaerts, R. A. Borchardt, M. MaloneMcNeal, and J. Archambault-Schexnayder. 1985. Intrahepatic assembly of very low density lipoproteins: varied synthetic response of individual apolipoproteins to fasting. J. Biol. Chem. 260:14137-14144.

27. Swift, L. L., R. J. Padley, and G. S. Getz. 1987. Differential labeling of rat hepatic Golgi and serum very low density lipoprotein apoprotein B variants. J. Lipid Res. 28:207-215.

28. Zick, Y. 1989. The insulin receptor: structure and function. Crit. Rev. Biochem. 24:217-269.

29. Capasso, J. M., T. W. Keenan, C. Abeijon, and C. B. Hirschberg. 1989. Mechanism of phosphorylation in the lumen of the Golgi apparatus: translocation of adenosine 5'-triphosphate into Golgi vesicles from rat liver and mammary gland. J. Biol. Chem. 264:52335240 .

30. Powell, M. A., and J. R. Glenney. 1987. Regulation of calpactin I phospholipid binding by calpactin I light-chain binding and phosphorylation by $\mathrm{p}^{\mathrm{v}-\mathrm{src}}$. Biochem. J. 247:321-328.

31. Berry, E. M., E. Ziv, and H. Bar-On. 1981. Lipoprotein secretion by isolated perfused livers from streptozotocin-diabetic rats. Diabetes. 21:402-408. 